\title{
Sinais dermatológicos clássicos na medicina veterinária
}

\author{
Classic dermatological signs in veterinary medicine \\ Carlos Eduardo LARSSON ${ }^{1}$ \\ ${ }^{1}$ Universidade de São Paulo, Faculdade de Medicina Veterinária e Zootecnia, \\ Departamento de Clinica Médica, São Paulo - SP, Brasil
}

\begin{abstract}
Resumo
Arrolam-se os sinais dermatológicos evidenciados na rotina da clínica dermatológica, que permitem aventar um diagnóstico presuntivo ou até estabelecê-lo cabalmente. Os dezesseis sinais reunidos envolvem quadros dermatopáticos etiologicamente relacionados às enfermidades autoimunes, infecciosas, parasitárias, alérgicas, endócrinas, psicopáticas, disqueratinizantes, neoplásicas e genodermatósicas.
\end{abstract}

Palavras-chave: Sinal. Semiogênese. Dermatites. Dermatoses.

\begin{abstract}
Dermatological signals observed in routine dermatologic clinical practice, which allow producing any presumptive diagnosis or to establish it fully, are listed. The 16 signals gathered are related to autoimmune, infectious, parasitic, allergic, endocrine, psychopathic, neoplasic, genetic and of abnormal cornification diseases.
\end{abstract}

Keywords: Signal. Semiogenesis. Dermatitis. Dermatosis.

\section{Introdução}

Os objetivos desse artigo foram compulsar e caracterizar os sinais dermatológicos além de facilitar a interlocução entre clínicos veterinários, mormente os dermatológos, sobre uma plêiade de manifestações, clinicamente evidenciáveis, que povoam o conhecimento dermatológico. Com grande frequência, o clínico confronta-se com epônimos, sinais ou mesmo síndromas cujo significado não se explicita de per se em sua designação (SAMPAIO; RIVITTI, 2007).

Há pouco tempo, no seio da medicina veterinária, à medida que se anglicizam os textos clínicos, abandonando-se a escola europeia, tradicional e vetusta, e abraçando-se o denominado americanismo ou americanização da semiotécnica, o termo "sinal" passou a substituir a clássica terminologia "sintoma", ou seja, os animais não mais teriam sintomas, mas, sim, simplesmente, sinais clínicos!

\footnotetext{
${ }^{1}$ Do grego: súmptõma, atos. Do latim medieval: symptoma, âtis - sintoma (1661). Do latim: signãlis, e; signum - sinal (1130) (HOUAISS; VILLAR, 2009).
}

Embora tradicionais semiológos médicos brasileiros, tais como o goiano Porto (2011) na sexta edição de seu tratado "Semiologia Médica", de 2011, considera que se possa utilizá-los como termos sinonímicos, também ressalta aquele tratadista que não são elas expressões exatamente sinônimas, por mais que sejamos tentados a igualá-las.

Ao longo deste artigo, considerar-se-á sinal a expressão que, segundo o destacado semiólogo veterinário brasileiro Eduardo Harry Birgel, docente com formação germânica, aposentado pela Faculdade de Medicina Veterinária e Zootecnia da Universidade de São Paulo, tão bem caracterizou, ao longo de suas preleções e escritos, com o significado de "manifesta-

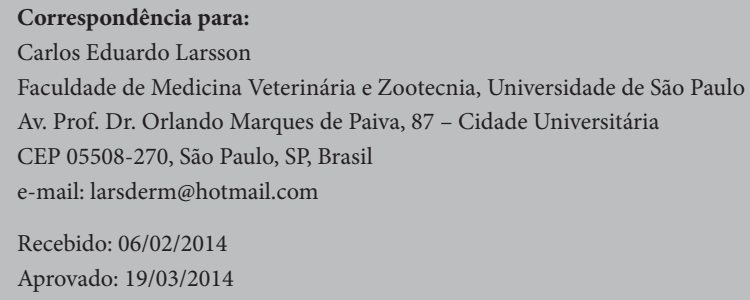


ções clínicas induzidas, observadas ou colhidas pelo clínico veterinário”. Discorreu ainda Birgel (1995) que "sinal não se constitui em simples observação de uma alteração de caráter clínico, mas sim da avaliação de uma reação ou manifestação do paciente eliciada pelo clínico", ou seja, "o raciocínio leva a uma conclusão".

Esse enfoque conceitual tem guarida em outros semiogenólogos e dicionaristas brasileiros, argentinos e europeus (MAREK; MONSKY, 1965; PORTO; ZICKER, 2011; STAFF, 1992; WHEELER, 1999). Com definições muito similares, caracterizam "sinal" como fenômeno, característica, sintoma objetivo de uma determinada enfermidade que o profissional, no senso lato da atividade clínica, elicia, provoca ou reconhece.

Estabelecido o enfoque conceitual de sinal, passa-se a arrolar os 16 sinais dermatológicos bem conhecidos e caracterizados na prática da dermatologia veterinária brasileira. Cotejando-se com 49 sinais dermatológicos, da prática médica do paciente dermatopata humano (SAMPAIO; RIVITTI, 2007), verifica-se evidente similitude de parte desses.

Assim, pôde-se, ao longo de 40 anos de clínica dermatológica do autor, reunir os sinais detalhados a seguir, alguns deles eponimados, por justiça, com nomes de médicos veterinários brasileiros.

\section{Asa de Borboleta}

Tal sinal caracteriza bem a lesão que assesta na face de caninos, por sobre o plano nasal, na configuração de uma borboleta com asas abertas, daí, também em outros idiomas, ser igualmente denominada "butterfly lesion" ou "ala de mariposa", respectivamente, em inglês e espanhol. Tal configuração gerou também, sinonimicamente, a designação de lesão "em vespertílio", por lembrar o contorno de um morcego com asas em abdução².

Trata-se de Sinal que caracteriza lesão tegumentar típica de quadros lúpicos, evidenciados na forma frus-

${ }^{2}$ Relativo aos vespertlionídeos, família de pequenos morcegos insetívoros, com centenas de espécies, de regiões tropicais ou temperadas (HOUAISS; VILLAR, 2009). ta do lúpus eritematoso, qual seja, a discoide (LED) ou mesmo na forma sistêmica (LES) da enfermidade autoimune, agravada que é pela radiação lumínica por sobre a área, no geral, de pelame rarefeito e fotoexposta. Distribui-se por além do dorso do plano nasal alcançando, com frequência, a região periorbitária (Figura 1).

A lesão tem base eritematosa, sendo encimada por deposição crostosa hemática, melicérica ou "em canela e açúcar".

Originalmente, foi descrita em pacientes humanos com lúpus eritema cutâneo agudo, que apresentam eritema confluente nas áreas malares e na fronte.

Segundo Sampaio e Rivitti (2007), esse Sinal se constitui em um dos onze critérios do American College of Reumatology empregado para o diagnóstico, também, do lúpus eritematoso sistêmico.

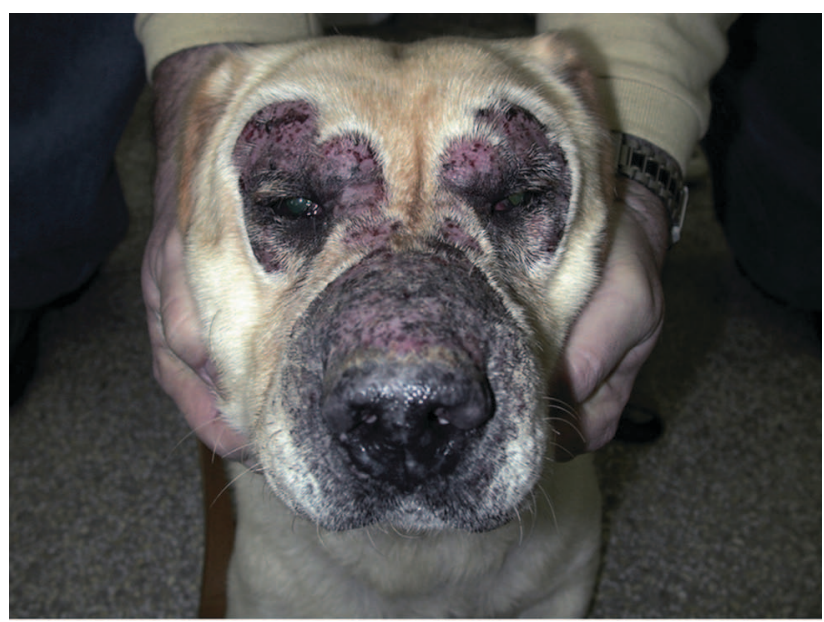

Figura 1 - Sinal de asa de borboleta - Lesão bilateral alopécica, eritematosa de plano nasal e região periorbitária. Crostas hemáticas dispersas. Discromia do espelho nasal

Fonte: (LARSSON, 2014)

\section{Asboe - Hansen}

Constitui-se em Sinal (Nikolky indireto, "indirect Nikolsky sign"), variante daquele de Nikolsky. Descrito em 1960, pelo dinamarquês Gustav Asboe-Hansen, é evidenciado, se bem que raramente, em animais dermatopatas acometidos, tal como os pacientes humanos, por penfigoide bolhoso ou pênfigo, mormente o foliáceo. Quanto mais profundo for o pênfigo, já que 
a clivagem é subpidérmica, mais facilmente é induzido e perpetuado tal Sinal. Para eliciá-lo, aplica-se compressão digital verticalizada por sobre formação bolhosa que se expande, aumentando seu diâmetro (MAREK; MOKSY, 1965).

Em dermatologia humana, utiliza-se na diferenciação diagnóstica entre pênfigo vulgar, em que está habitualmente presente, do penfigoide bolhoso, já que nesta modalidade mimética dos pênfigos verdadeiros não é evidenciado. Está também relatado na Sindroma da pele escaldada estafilocócica de recém-nascidos, também chamada dermatite esfoliativa de Ritter.

\section{Borra de Café}

O comuníssimo Sinal é evidenciado em casos de otopatias externas parasitárias, decorrentes de otoacarioses acarretadas pelo Otodectes cynotis.

Quando de otoscopia, depara-se com deposição ceruminosa enegrecida, por vezes encimada por deambulação acariana.

O aspecto enegrecido do cerúmen pressupõe-se derivar do sangue proveniente da parasitose. Tal aspecto retrata o pó de café após a coação (Figura 2).

Em quadros seborreicos com assestamento meatal pode haver também deposição ceruminosa enegrecida que deve ser diferenciada da otite parasitária por semiologia armada.

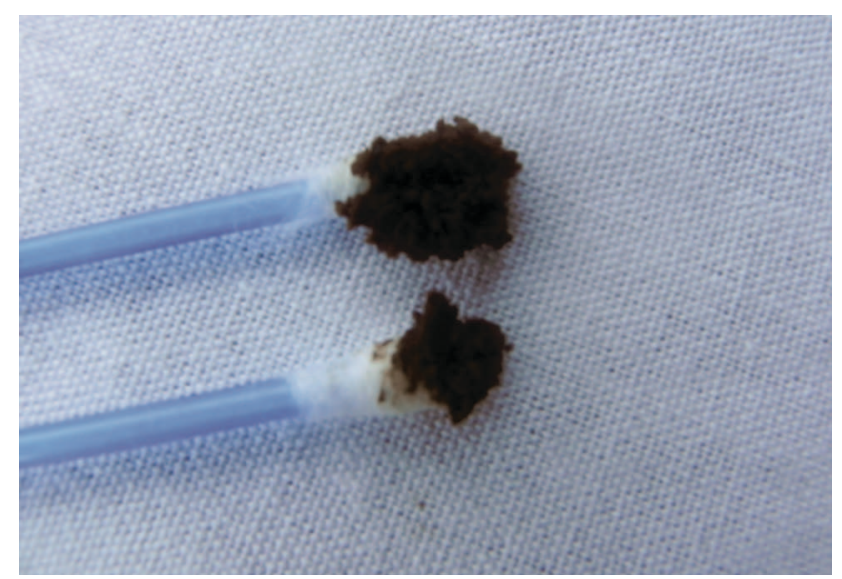

Figura 2 - Sinal de borra de café - cerúmen enegrecido, provindo de meato acústico externo de canino com otite externa ceruminosa, disposto em extremidade de hastes de algodão

Fonte: (LARSSON, 2014)

\section{Bruxismo Símile}

O bruxismo ${ }^{3}$, briquismo ou bricomania constituise, na medicina humana, em manifestação neurótica, tensional ou decorrente de estresse. Há um ranger de dentes devido à contração rítmica dos masseteres e de outros grupos musculares mastigatórios. A médio prazo, leva ao desgaste anormal das cúspides dentárias.

Em dermatologia veterinária, em alergopatias tegumentares crônicas, a exemplo da dermatite atópica canina há, face ao longo decurso e às frequentes recidivas de episódios de prurido epicrítico, um evidente desgaste dentário dos incisivos (faces vestibular e/ou labial), pelo atritar dos dentes com a queratina pilar. O desgaste anômalo (Figura 3) mimetiza o briquismo, daí a denominação do Sinal de bruxismo símile.

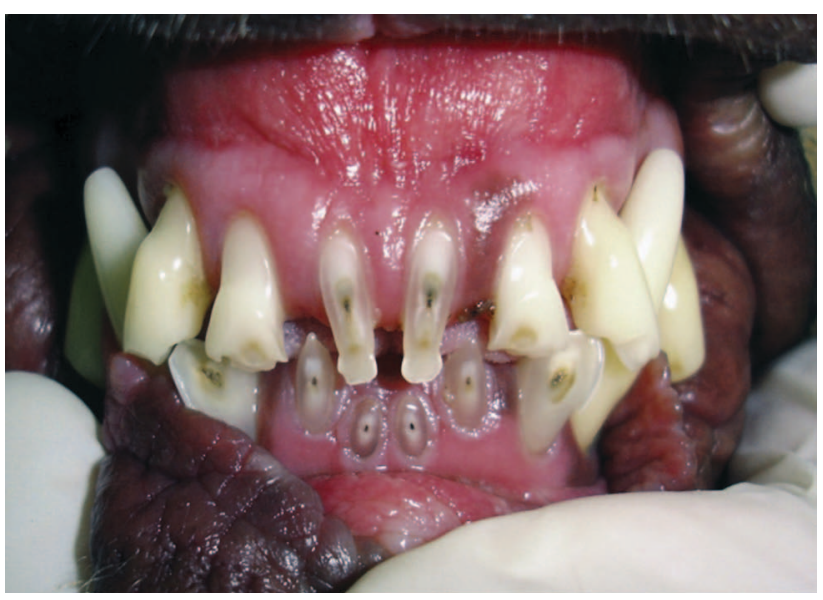

Figura 3 - Sinal de bruxismo símile - desgaste de dentes incisivos (face labial) decorrente de mordicar de tegumento de canino atópico, com prurido epicrítico crônico

Fonte: (LEON-ROMAN, 2014)

\section{Caixa de Fósforo}

Este intrigante Sinal, na verdade, não é evidenciado no paciente animal, mas, sim, no seu proprietário ou preposto. Deve o clínico dermatólogo saber de sua existência, estar alerta para sua eventual evidenciação e caracterização. Os proprietários, em geral, relatam com discurso conexo, ao longo da anamnese, a ocorrência de lesões e sintomas por eles apresentados, tipificados por prurido epicrítico e/ou biopsiante em áre-

${ }^{3}$ Do grego brýchõ: ranger os dentes (PACIORNIK, 1978). 
as corpóreas não necessariamente expostas ao contato com o paciente animal.

É contumaz o relato da sensação de intensa prurigem, pinicação, de ambulação de parasitos pelo corpo, de forma diuturna.

As pressupostas lesões caracterizam-se por erosões, escoriações, colarinhos epidérmicos, escamas, crostas, topograficamente dispostas em áreas acessíveis à coçadura, tais como: braços, antebraços, cintura pélvica, omoplata, tronco superior, pescoço (Figura 4).

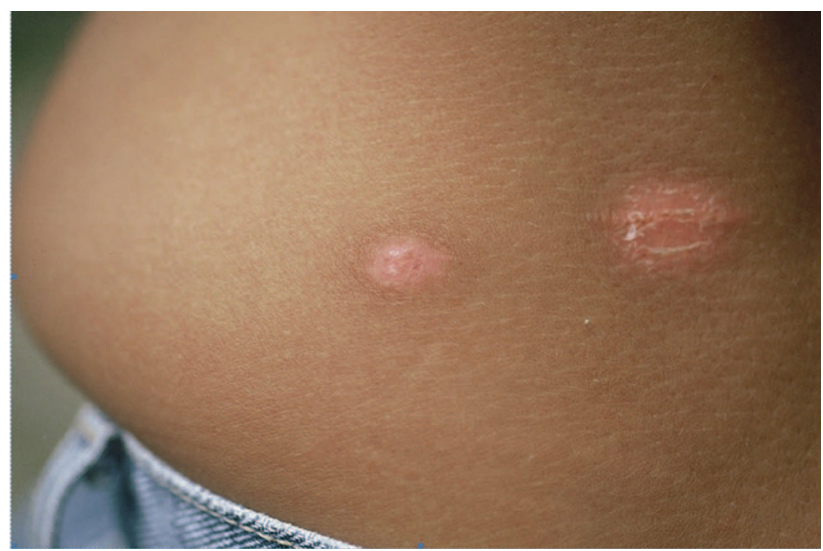

Figura 4 - Paciente acarafóbica ("Sinal de caixa de fósforo") - lesões escoriadas eritêmato-descamativas, autoinduzidas, em cintura pélvica

Fonte: (LARSSON, 2014)

A manifestação sintomática pressuposta é tão bem assegurada pelo dono, convencido de sua existência, que pessoas da família ou empregados também passam a senti-la. Os franceses denominam tal condição de "folie a deux" ou "folie a trois". Os pacientes acometidos são verdadeiramente delirantes, acarofóbicodos e portadores do Síndroma de Ekbom ${ }^{4}$.

A designação do sinal recebe distintas denominações em outros idiomas, tais como: Matchbox sign", "Signe de la boite d'allumette", "Signo de la caja de fosforo" ou "Signo de la caja de cerilla". Tal denominação provém do fato de o proprietário, que conduz o animal ao clínico veterinário, portar consigo diversos

${ }^{4}$ Síndroma descrito pelo neurologista sueco Karl Axel Ekbon (1938), sob a denominação de delírio parasitário dermatozooico. Em 1946, Wilson Miller consagrou o epônimo - Sindrome de Ekbom. exemplares de caixas de fósforo ou frascos de remédio, no geral revestidos por algodão, onde depositam o pretenso parasito que, na verdade, são fragmentos de sua própria pele avulsionada com auxílio das unhas (figuras 5 e 6 ).

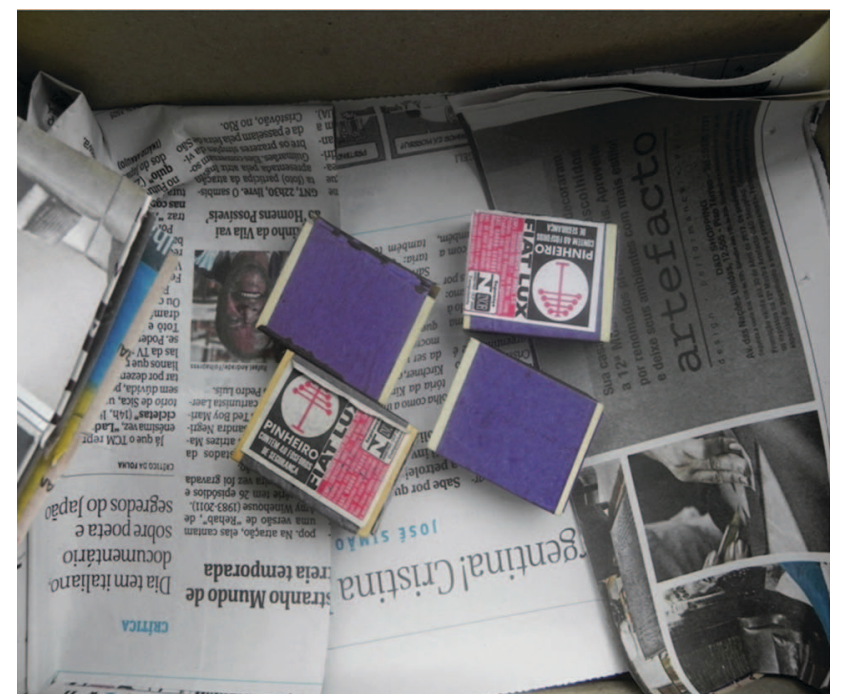

Figura 5 - Caixas de Fósforo no interior de embalagem de correio expresso

Fonte: (LARSSON, 2014)

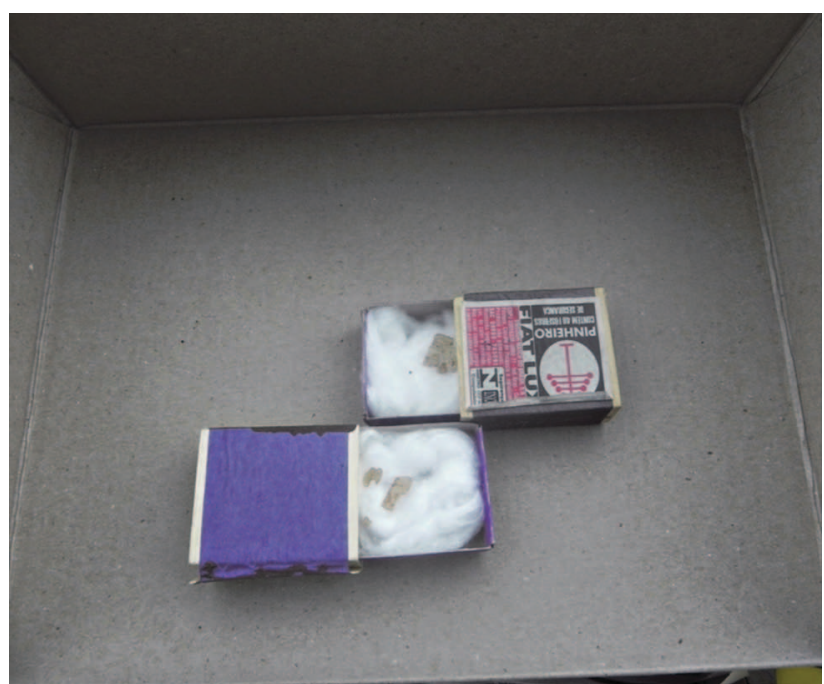

Figura 6 - Caixas de fósforo com fragmentos de pele, removidos por paciente acarofóbica, dispostos por sobre algodão

Fonte: (LARSSON, 2014)

Obviamente, os animais nada apresentam em seu tegumento que caracterize uma dermatozoonose, a exemplo de escabiose, queiletielose, otodecidose, dermatofitose. 
Não é raro que se trate de caso derivado ao clínico veterinário por um dermatologista humano intrigado sobre a possibilidade de ter havido transmissão, ou mesmo para assegurar ao seu paciente que a enfermidade, na verdade, se constitui em psicopatia (psicose hipocondríaca monossintomática) (ESTELLITA-LINS; AZULAY; AZULAY, 2008), que necessita tratamento psiquiátrico ou psicológico.

\section{Cauda em Batom}

Tal Sinal é observado na extremidade distal da cauda de caninos, que apresenta área de alopecia localizada, com pele preservada, embora, por vezes, pigmentada (figura 7), em caninos acometidos por dermatomiosite familiar canina ou dermatopatias isquêmicas outras (HNILICA, 2011; MILLER JR.; GRIFFIN; CAMPBELL, 2013).

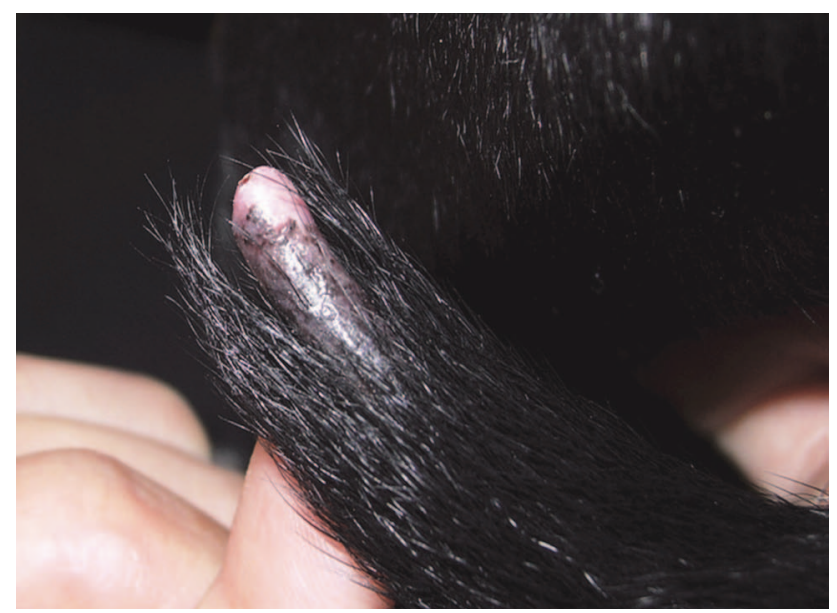

Figura 7 - Sinal de cauda em batom - lesão alopécica, discrômica, na extremidade distal da cauda de canino acometido por dermatomiosite familiar

Fonte: (LARSSON, 2014)

Pressupostamente derivada de hipóxia tegumentar de base gerando atrofia folicular, que se agrava quando de traumas mecânicos.

\section{Cauda-de-Rato}

O Sinal da cauda-de-rato é mais um dos ditos patognomônicos da dermatologia veterinária. Bastante frequente em quadros hipofuncionais das glândulas tireoides caninas.
Em áreas, como a porção dorsal da cauda, submetida ao atrito repetido no piso quando do sentar do animal, há perda pilar. Nos hipotireoideos a ausência do anágeno, pela falta de níveis tiroxinêmicos normais, leva à persistência do telógeno pilar sem a substituição dos pelos perdidos. Evidencia-se área alopécica linear com preservação da integridade da pele que, por vezes, se mostra simplesmente hiperpigmentada (figuras 8 e 9).

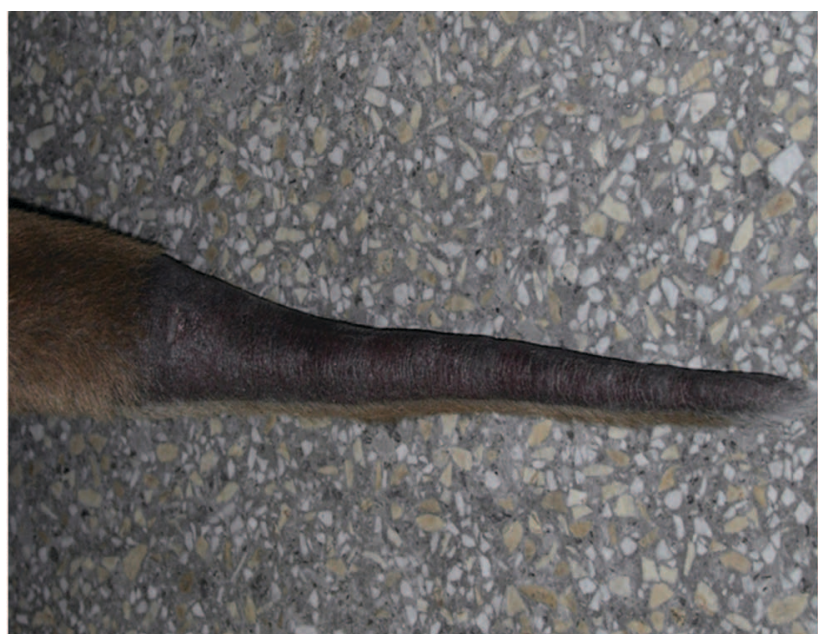

Figura 8 - Sinal de cauda-de-rato - lesão alopécica localizada com hiperpigmentação dorsal em cauda de canino hipotireoideo

Fonte: (LARSSON, 2014)

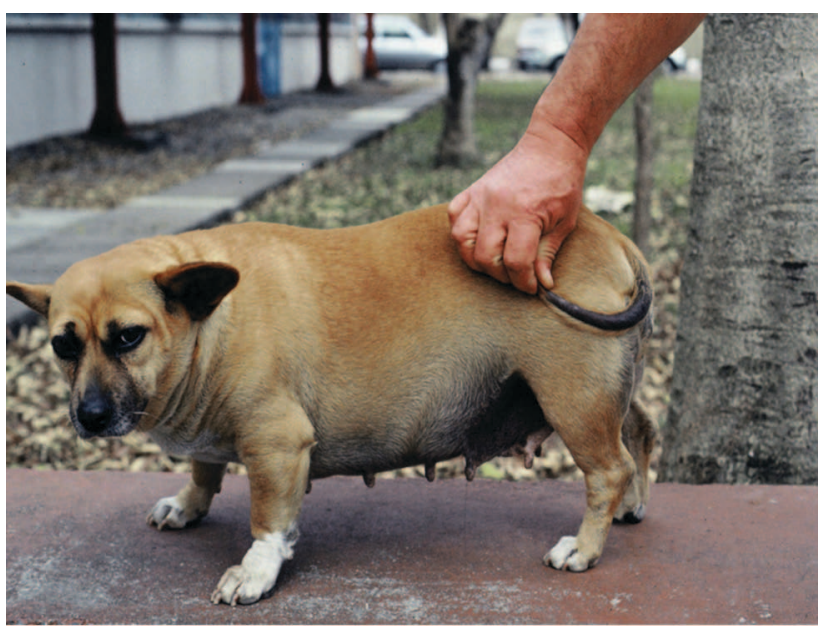

Figura 9 - Sinal de cauda-de-rato - canino hipotireoideo com alopecia e hiperpigmentação ao longo da região coccígea. Destaca-se a presença concomitante do Sinal de Jericó e de evidente obesidade Fonte: (LARSSON, 2014)

\section{Godet}

Trata-se, quiçá, do mais clássico dos sinais dermatológicos. Além do epônimo é também conhecido por 
Cacifo ou Sinal de cacifo. Ocorre quando de pressão exercida digitalmente por sobre pele edemaciada assestada em região adjacente à estrutura óssea. A depressão gerada é conhecida por fóvea ${ }^{5}$, retratando o aspecto em taça (Figura 10). A positividade é retratada quando a depressão gerada não se desfaz de imediato após a descompressão.

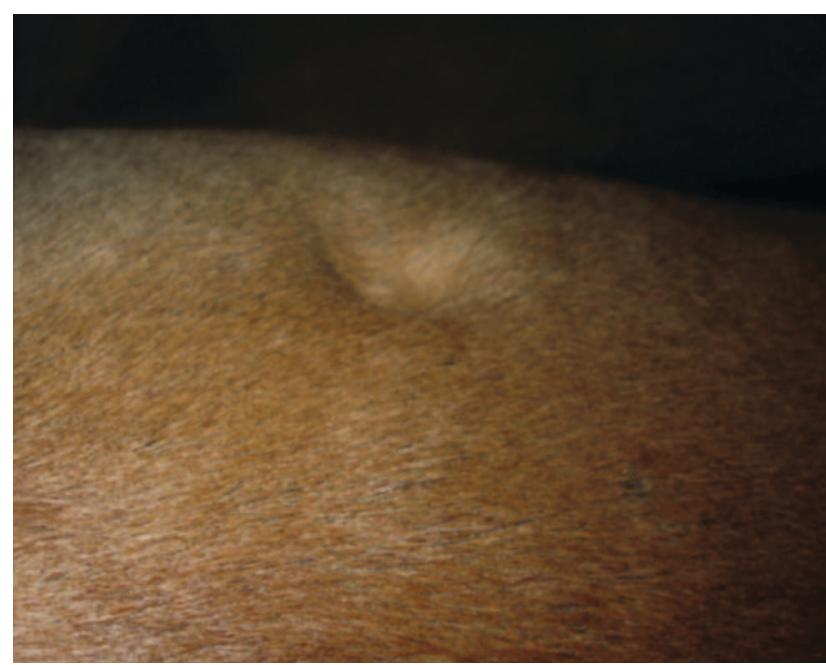

Figura 10 - Sinal de Godet - fóvea em pele edematosa Fonte: (LARSSON, 2014)

O Sinal de Godet está presente em áreas de edema de distintas origens, mas não em áreas de mucinose tegumentar, propiciando o diagnóstico diferencial.

\section{Jericó}

Trata-se de Sinal bem evidenciado e que se associa a outros ("cauda-de-rato", facies trágica) em caninos hipotireoideos.

Referido desde os anos 1990 por endocrinóloga veterinária paulista, geradora da eponimação, que de forma sagaz observou que em cães com hipofunção tireoideana, por aparentar intenso mixedema decorrente da deposição de mucopolissacarídeos por sobre o plano nasal, gera aumento de volume localizado, uniforme, distalmente no focinho (figuras 11 e 12), causando impressão de ampliação da região.

${ }^{5}$ Do latim fóvea: buraco, fossa, cova (HOUAISS; VILLAR, 2009).

\section{Larsson}

Constitui-se em Sinal comumente observado na rotina da clínica dermatológica de caninos, equinos e 
até de felinos. É facilmente evidenciado em quadros disqueratinizantes, em áreas ainda hirsutas, principalmente com pelame escuro, no geral tronculares dorsais que, quando do passar dos dedos, em paralelo e perpendicularmente, leva à deposição, de imediato, de escamas pitiriásicas ou furfuráceas em configuração linear paraleliforme, com aspecto de trilho (figuras 13 e 14).

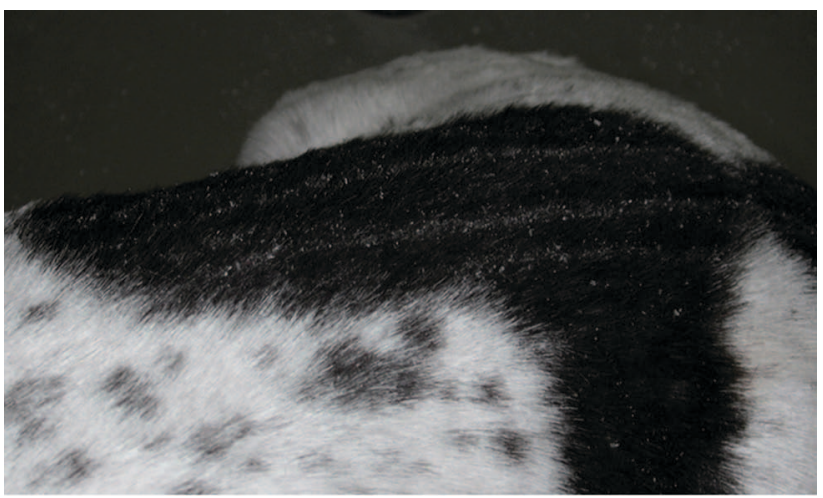

Figura 13 - Sinal de Larsson - aspecto dorsolateral de regiões torácica e lombo sacral, de pele hirsuta, mas disqueratinizada, com deposição linear e paralela de escamas furfuráceas, em aspecto de trilhos

Fonte: (LARSSON, 2014)

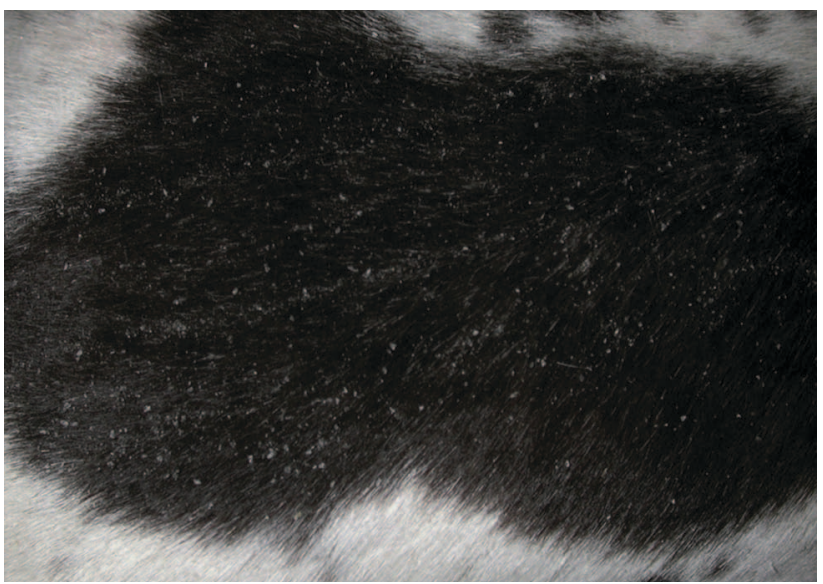

Figura 14 - Aspecto da região lombo sacral dorsal com SiFonte: (LARSSON, 2014) nal de Larsson (figura 13 em maior detalhe)

\section{Nikolsky}

Clássico sinal, caracterizado, em suas primícias, em 1896, pelo dermatologista russo Pyotr Vasilyvitch Nikolsky, em Kiev (Ucrânia), em pacientes humanos acometidos pelos pênfigos, mormente o clássico ou Pênfigo de Cazenave, bem como em dermatoses acantolíticas, tal como a necrólise epidérmica tóxica ou Síndroma de Lyell (SAMPAIO; RIVITTI, 2007). A acantólise, subcórnea ou intraepidérmica imunemediada, gera fragilidade da adesão intercelular. Assim, ao se friccionar a pele do paciente canino penfigoso com a ponta do dedo envolto em gaze, ou atritando-a com objeto de ponta romba (clip de papel ou tampa de caneta esferográfica), gera-se o deslizamento de células da camada espinhosa, ocasionando efêmera coleção líquida e, a seguir, mais duradouro, retalho epidérmico (figura 15).

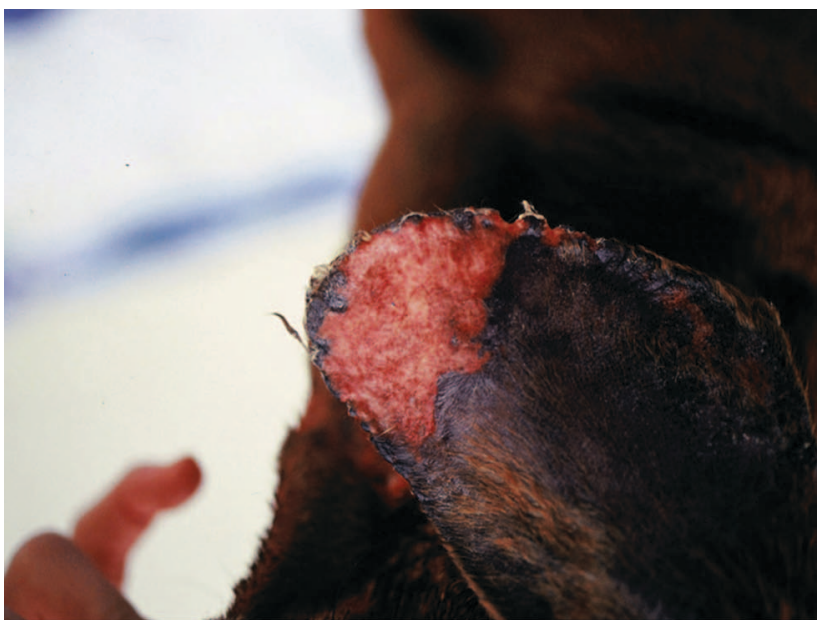

Figura 15 - Sinal de Nikolsky - erosão, bordejada por retalho epidérmico, em extremidade de pavilhão auricular, resultante de atrito com dedo envolto em gaze, em canino acometido por necrólise epidérmica tóxica

Fonte: (LARSSON, 2014)

\section{Noz-moscada}

Sinal corriqueiro traduzindo a senectude do animal, fato este nitidamente fisiológico, ou observado em quadros tegumentares endocrinopáticos.

A pele apresenta-se como uma noz-moscada ${ }^{6}$ (Myristica fragrans) com superfície ralada, em geral, nas regiões meso e hipogástrica ventral, traduzindose por área discrômica, entremeando máculas hipo e hiperpigmentadas com aspecto "em favo" (figura 16).

${ }^{6}$ Especiaria obtida a partir da semente do fruto da moscadeira (Myristicaceae), originária das Ilhas Molucas (Indonésia), hoje cultivada no Brasil (Bahia), Índia, Nova Guiné, Singapura, Colômbia. Utilizada na culinária, como condimento; na indústria farmacêutica e de perfumaria. Intensamente comercializada desde os tempos romanos, na Idade Média e na Era dos Descobrimentos. 


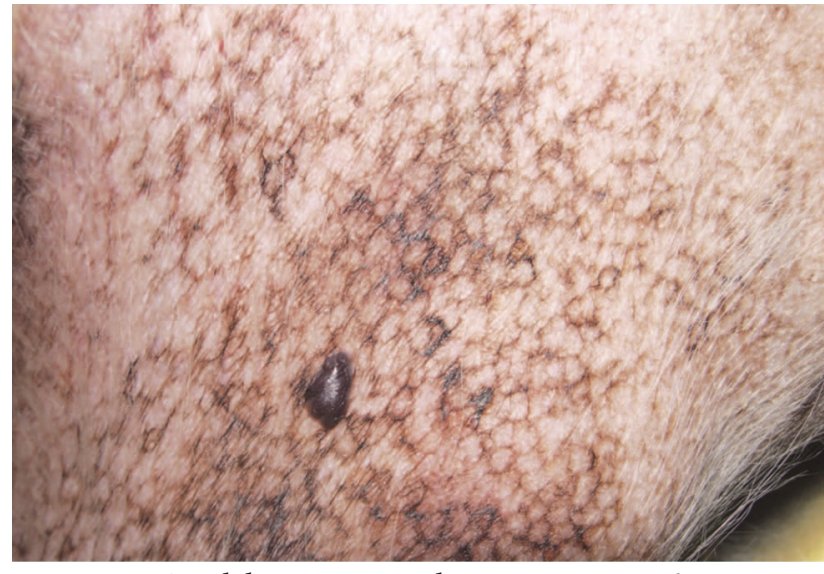

Figura 16 - Sinal de noz-moscada - região mesogástrica com área discrômica, entremeando máculas hipo e hiperpigmentadas com aspecto "em favo"

Fonte: (LARSSON, 2014)

\section{Orelha em Envelope}

Sinal este bastante corriqueiro na clínica dermatológica de felinos, mormente no tegumento daqueles heliófilos de pelame claro, rarefeito e de íris clara. A exposição crônica à radiação ultravioleta gera alopecia, hiperplasia e displasia epidérmica, hiper e ou paraqueratose, fibrose e elastose dérmica, traduzindo-se no fletir da extremidade distal dos pavilhões auriculares. A flexão da ponta da orelha de encontro ao terço médio do pavilhão leva ao aspecto de verso de envelope (figuras 17 e 18).

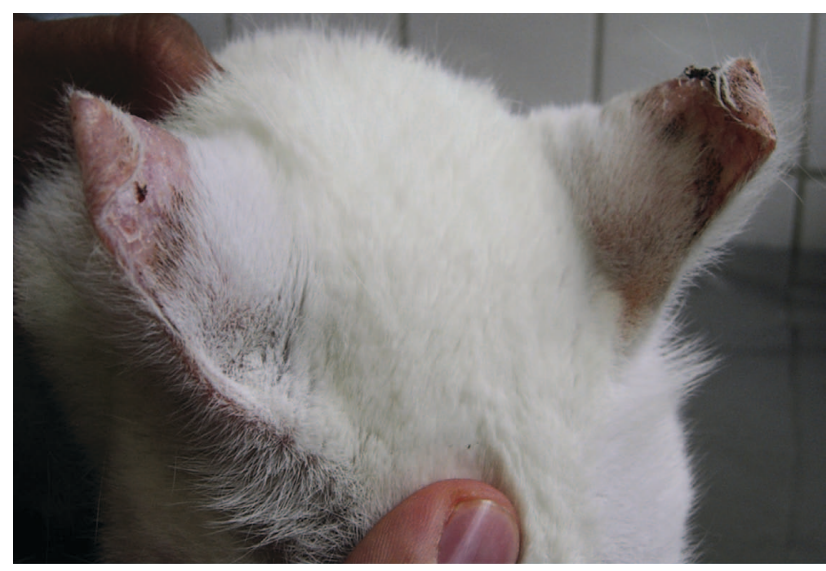

Figura 17 - Sinal de orelha em envelope - pavilhões auriculares semifletidos em felino acometido por queratose actínica (aspecto dorsal)

Fonte: (LARSSON, 2014)

Trata-se de sinal característico de fotodermatoses, a exemplo da queratose actínica (solar), de quadros pré ou francamente neolásicos (carcinoma espinocelular

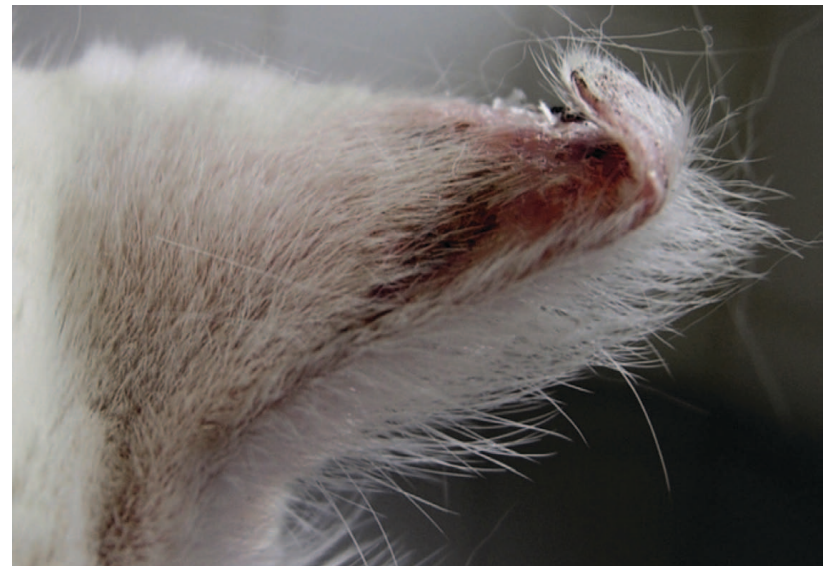

Figura 18 - Sinal de orelha em envelope - pavilhão auricular destro semifletido (maior detalhe) em felino acometido por queratose actínica (aspecto laterodorsal)

Fonte: (LARSSON, 2014)

in situ ou Doença de Bowen, epitelioma basocelular superficial, carcinoma espinocelular).

\section{Pele Encabidada}

Eventualmente, tal sinal pode ser evidenciado em casos graves de desidratação, quando da distensão tegumentar dorsal (torácica ou toracolombar) praticada pelo clínico veterinário no decorrer do exame físico, buscando caracterizar a elasticidade da pele relacionada ao grau de hidratação orgânica, destarte a resultante, qual seja, a persistência da prega formada é relativamente efêmera (figura 19).

No entanto, nos casos de genodermatoses congênitas de longo decurso, o aumento da elasticidade, re-

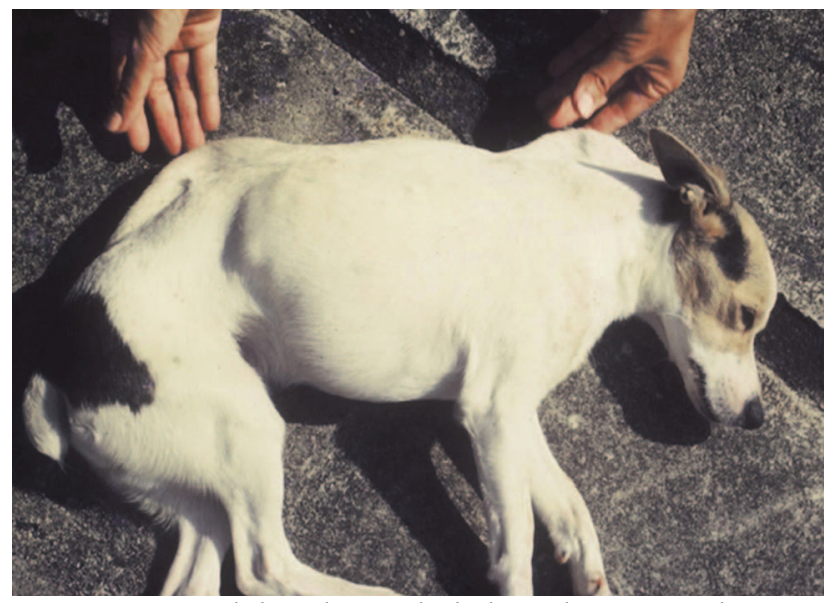

Figura 19 - Sinal de pele encabidada - plica cervical e toracolombar em canino desidratado (caso de síndroma urêmico em leptospirose canina)

Fonte: (LARSSON, 2014) 
tratado por grande distensão do tegumento, gera uma plica duradoura (figuras 20 e 21), semelhante àquela de peças de vestuário deixadas por muito tempo dispostas em cabides.

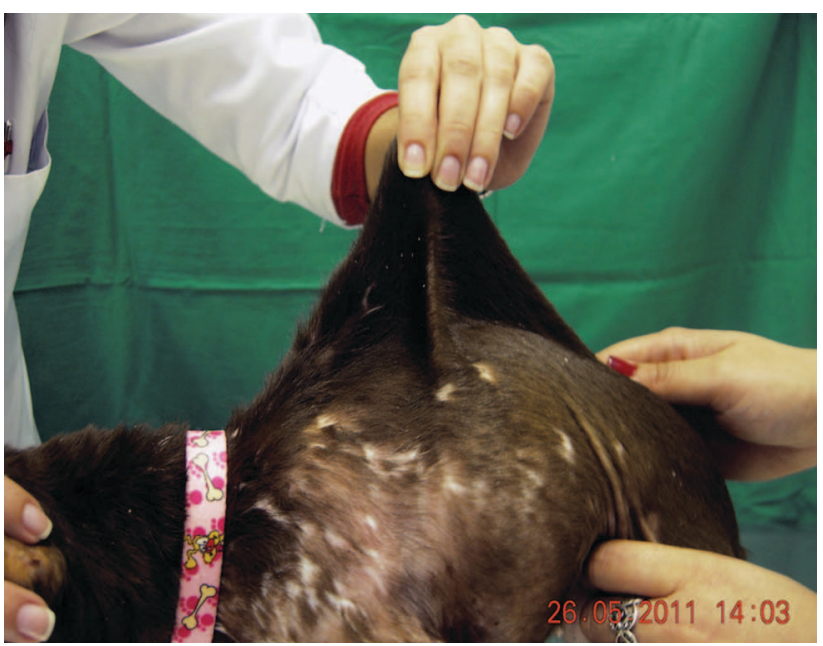

Figura 20 - Sinal de pele encabidada - distensão tegumentar toracolombar exagerada em canino portador da Síndrome de Ehlers-Danlos. Destacam-se lesões caducas, escapulares e torácicas, branquicentas disseminadas, decorrentes de cicatrizes
de pele facilmente rasgável Fonte: (LARSSON, 2014)

Fonte: (LARSSON, 2014)

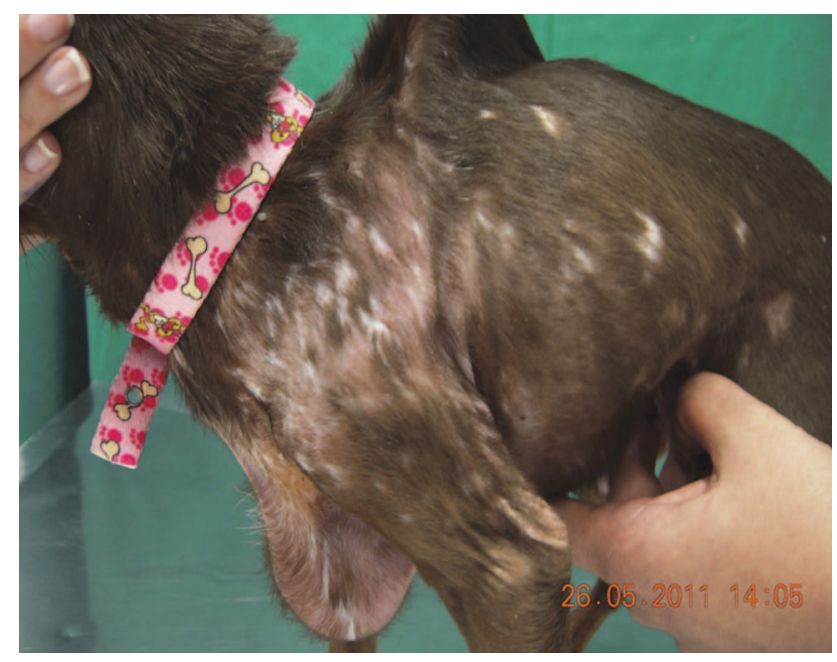

Figura 21 - Sinal de pele encabidada - distensão tegumentar toracolombar e plica cérvico-torácicaventral em canino portador da Síndroma de Fonte: (LARSSON, 2014) Ehlers-Danlos (canino da figura 20)

É sinal característico de enfermidades colagênicas hereditárias, tal como a dermatoparaxis, astenia cutânea ou Síndrome de Ehlers-Danlos, observada em inúmeras espécies animais.

\section{Rosário}

Sinal cuja denominação foi extraída da configuração do objeto destinado à prática religiosa dos católicos ${ }^{7}$.

As lesões, miméticas a ele, derivam de formações nodulares, gomosas ou mesmo de linfonodos no trajeto de linfáticos, provenientes da ascenção de processo inflamatório de etiologia infecciosa, a partir do cancro primário (esporotricoma, leishmanioma, etc.) de inoculação, de fungos dimórficos ou de protozoários. Nos quadros de esporotricose ou leishmaniose é frequente o surgimento do Sinal do Rosário, respectivamente, esporo ou leishmaniótico. Trata-se de sinal patognomônico dessas enfermidades (figuras 22 e 23). Pode ser também detectado, se bem que raramente, em quadros neoplásicos, tegumentares linearmente a partir do foco primário da formação blastomatosa.

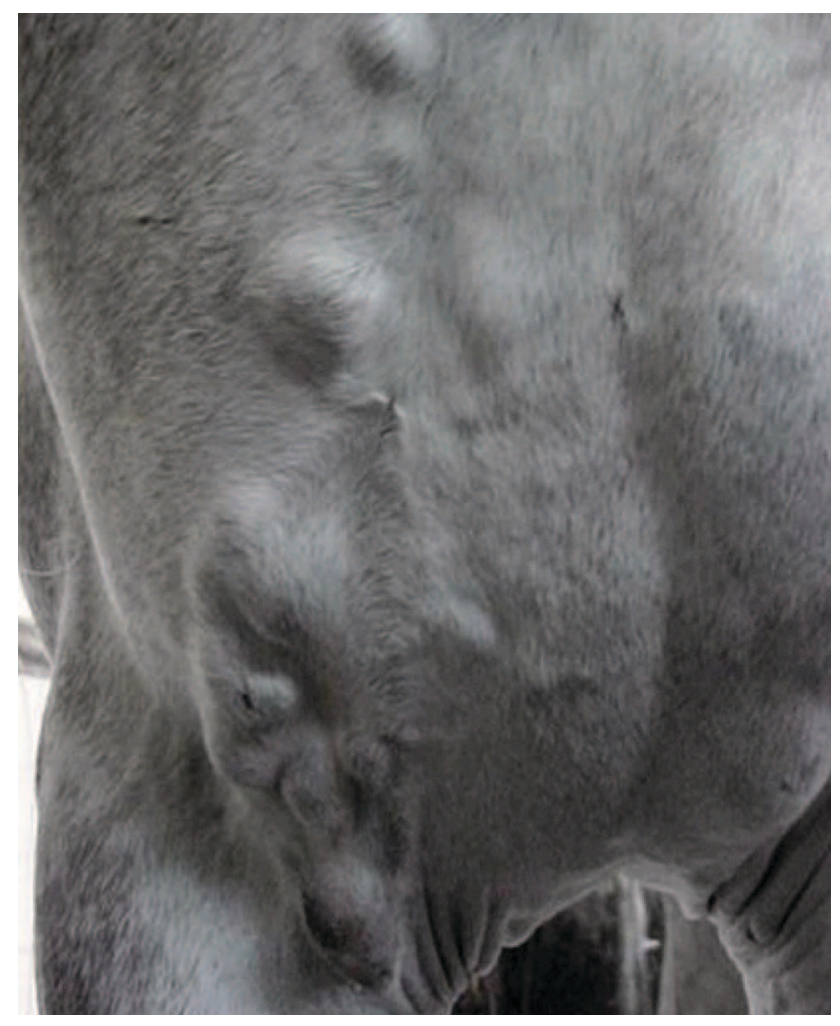

Figura 22 - Sinal de Rosário - lesões pápulo-nódulo-tumorais em região cervical destra distal, em configuração linear, de equino com leishmaniose tegumentar

Fonte: (BACCARIN, 2014)

${ }^{7}$ Enfiada de 165 contas, corresponde a 15 dezenas de orações distintas. A divisão em três partes iguais foi designada de terço. 


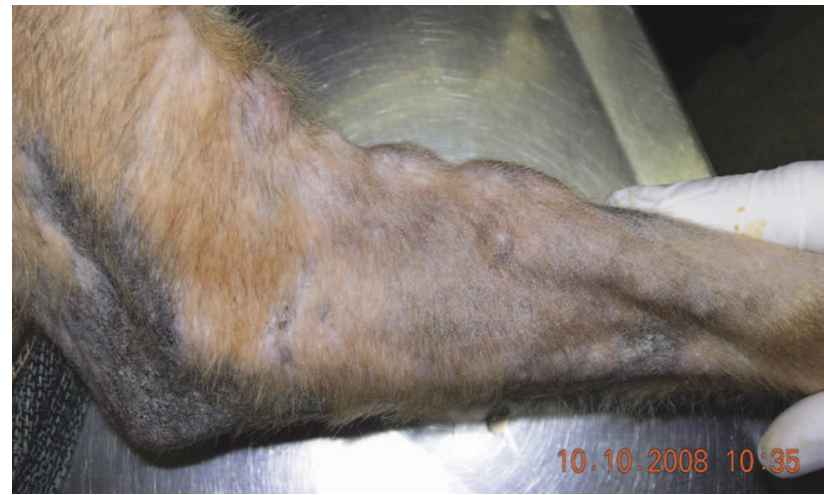

Figura 23 - Sinal de Rosário - lesões pápulo-tumorais em membro torácico direito, em configuração linear, em área de alopecia parcial de canino esporotricótico

Fonte: (LARSSON, 2014)

\section{Salpico de Lama}

Trata-se de Sinal clássico, bem caracterizado em casos de pênfigo foliáceo humano, na modalidade endêmica ("pênfigo brasileiro" ou "sul-americano" ou, ainda, fogo-selvagem) (DIAZ et al., 1989; FURTADO, 1959). Foi referido, de forma magistral, por Vieira (1948), dermatologista brasileiro, na fase de evolução para a cura da enfermidade, denominada "aurora da cura".

No século passado, antes do advento da "era esteroidal" da terapia dos quadros vésico-bolhosos autoimunes, observava-se que pacientes com fogo-selvagem evoluíam com formas localizada (frusta), generalizada ou hiperpigmentada. Esta última era evidenciada em pacientes em fase de remissão da doença, mormente em áreas previamente lesadas, prestando-se como indicador precoce de remissão ou da cura do fogo-selvagem. As primitivas áreas e erodo-crostosas, exsudativas, úmidas, tornavam-se de aspecto macular, pigmentado, disseminado, dando um aspecto de barro salpicado (FURTADO, 1959).

O mesmo aspecto de lama salpicada é observado em pacientes caninos acometidos pelo pênfigo foliáceo (LARSSON, 2009; LARSSON, 2005), na modalidade clássica ou Pênfigo de Cazenave símile, naqueles graves casos eritrodérmicos e pustulares disseminados que ao cederem à terapia imunossupressora têm as lesões primitivas substituídas por lesões pigmentares residuais no geral indeléveis (figuras 24, 25, 26 e 27).

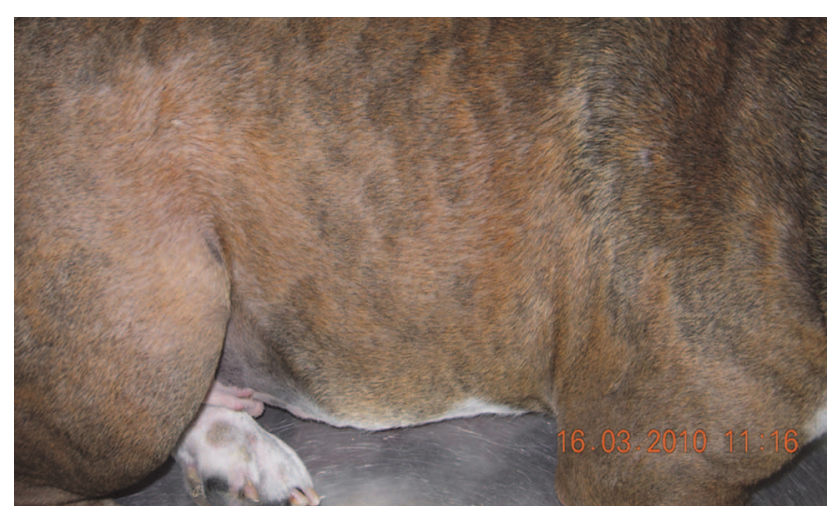

Figura 24 - Sinal de salpico de lama - lesões maculares hiperpigmentas disseminadas, em face lateral toracoabdominal de canino penfigoso (pênfigo foliáceo) após a terapia (aspecto de lama salpicada)

Fonte: (LARSSON, 2014)

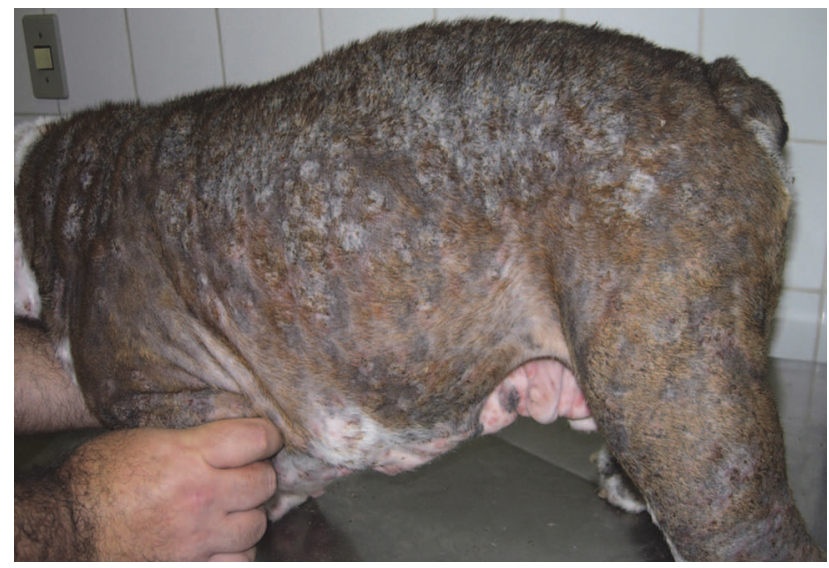

Figura 25 - Pênfigo foliáceo - lesões disseminadas de deposição de crostas, alopecia, em face lateral sinistra da região toracoabdominal de cão penfigoso (pênfigo foliáceo) Aspecto na pré-terapia do canino da Figura 24

Fonte: (LARSSON, 2014)

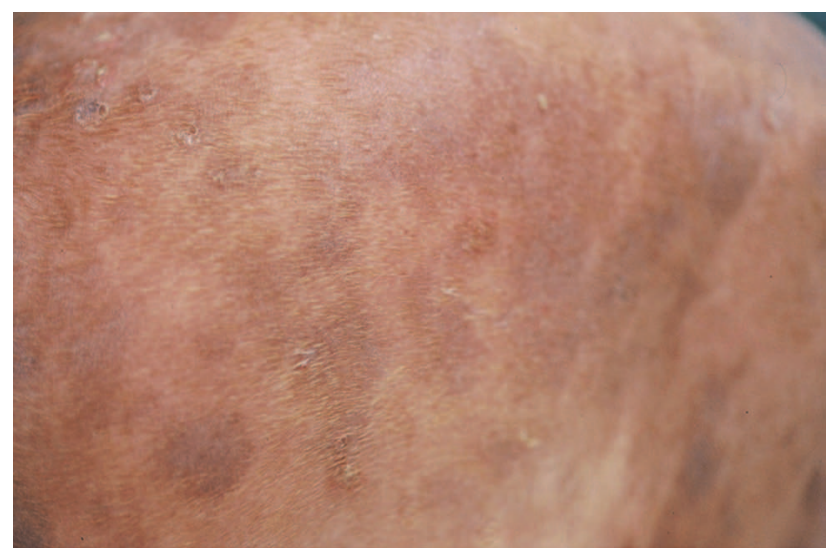

Figura 26 - Sinal de salpico de lama - lesões circulares e coalescentes de hiperpigmentação macular (regiões hipo e mesogástrica lateral sinistra). Destacam-se lesões caducas ("colarinho epidérmico") de áreas pustulares primitivas. Canino penfigoso no pós-terapia

Fonte: (LARSSON, 2014) 


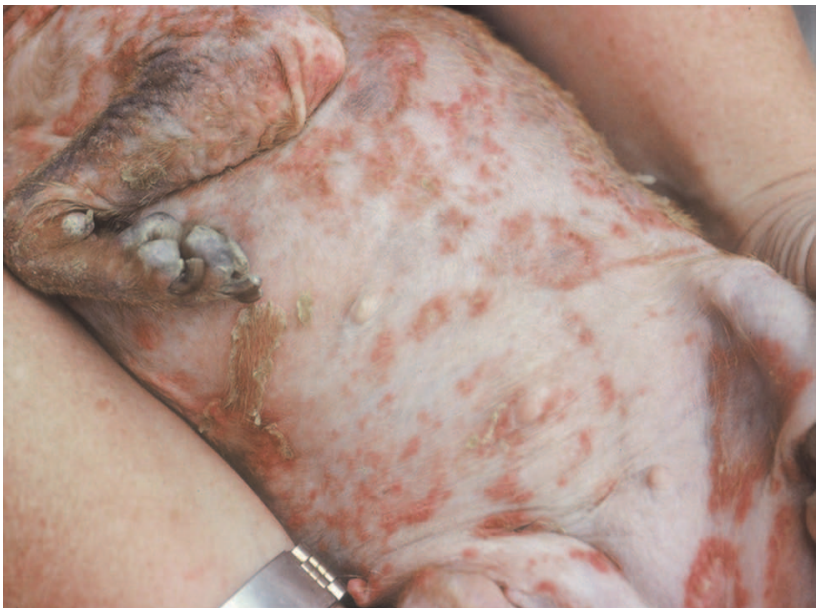

Figura 27 - Pênfigo foliáceo - lesões ventrais, na pré-terapia de pênfigo foliáceo canino. Aspecto pustular erosado (configuração circinada) disseminado em área abdominal ventral e úmero-radio-ulnar (canino da figura 26)

Fonte: (LARSSON, 2014)

\section{Referências}

AZULAY, D. R.; AZULAY, R. D.; AZULAY-ABUlAFIA, L. Dermatologia. 5. ed. Rio de Janeiro: Guanabara-Koogan, 2008. p. 656-63.

BIRGEL, E. H. Preleções de semiologia veterinária: semiologia geral. Telesimpósio: Ensino, pesquisa e extensão em medicina veterinária - EMBRATEL. Rio de Janeiro: Conselho Federal de Medicina Veterinária. Outubro de 1995.

DIAZ, L. A.; SAMPAIO, S. A. P.; RIVITTI, E. A.; MARTINS, C. A.; CUNHA, P. R.; LOMBARDI, C.; ALMEIDA, F. A.; CASTRO, R. M.; MACCA, L. A.; LAVRADO, C.; GUNTHER FILHO, H.; BORGES, P.; MINELLI, L.; EMPINOTTI, J. C.; FRIEDMAN, H.; CAMPBELL, I.; LABIS, R. S.; ANHALT, G. J. Endemic pemphigus foliaceus (fogo selvagem). I. Clinical features and immunopathology. Journal of the American Academy of Dermatology, v. 20, n. 4, p. 657-69, 1989.

EKBOM, K. A. Der präsenile dermatozoenwahn. Acta Psychiatrica et Neurologica Scandinavica, v. 13, p. 227-59, 1938.

ESTELLITA-LINS, C.; AZULAY, D. R.; AZULAY, R. D. Psicodermatologia, medicina psicocutânea e dermatologia psicossomática. In: AZULAY, D. R.; AZULAY, R. D.; AZULAY-ABULAFIA, L. Dermatologia. 5. ed. Rio de Janeiro: Guanabara-Koogan, 2008. p. 656-63.

FURTADO, T. A. Histopathology of pemphigus foliaceus. Archives of Dermatology, v. 80, p. 66-71, 1959.

HNILICA, K. A. Familial canine dermatomyositis. In: HNILICA, K. A. Small animal dermatology: a color atlas and therapeutic guide. 3. ed. St. Louis: Elsevier, 2011. p. 335-7.

HOUAISS, A.; VILLAR, M. S. Dicionário Houaiss da língua portuguesa. Rio de Janeiro: Objetiva, 2009. 1986 p.

LARSSON, C. E. Complexo pênfigo: fogo-selvagem símile (wild fire, fuego salvaje) - aspectos clínicos e epidemiológicos. In:
Histologicamente, há proliferação melanocítica intraepidérmica e consequente aumento da deposição melânica, incontinência pigmentar com acúmulo de melanina nos fagócitos dérmicos (DIAZ et al., 1989).

\section{Agradecimentos}

O autor agradece aos Médicos Veterinários Marco Antonio Leon Roman, Raquel Yvone Arantes Baccarin e Viviani de Marco pela cessão de parte das figuras que ilustram o artigo.

CONGRESS OF SMALL ANIMALS VETERINARIANS, 6., 2009, São Paulo. Anais... São Paulo: FIAVAC, 2009.

LARSSON, C. E. Wandering through the autoimmune dermatoses: pemphigus complex. In: WORLD CONGRESS OF THE WORLD SMALL ANIMAL VETERINARY ASSOCIATION, 30., 2005, Cidade do México. Proceedings... Cidade do México: FECAVA, 2005. p. 205.

MAREK, J.; MOKSY, J. Tratado de diagnóstico clínico de las enfermidades internas de lós animales domésticos. 3. Ed. Barcelona: Labor, $1965.606 \mathrm{p}$.

MILLER JR., W. H.; GRIFFIN, C. E.; CAMPBELL, K. L. Familial canine dermatomyositis. In: MILLER JR., W. H.; GRIFFIN, C. E.; CAMPBELL, K. L. Muller \& Kirk's small animal dermatology. 7. ed. St. Louis: Elsevier, 2013. p. 585-587.

PACIORNIK, R. Dicionário médico. 3. ed. Rio de Janeiro: Guanabara Koogan, 1978.

PORTO, C. C.; ZICKER, F. Princípios e bases para prática médica. In: PORTO, C. C. Semiologia médica. 6. ed. Rio de Janeiro: Guanabara Koogan, 2011. p. 3-15.

STAFF, S. Dicionário médico. 3. ed. Barcelona: Salvat, 1992.

SAMPAIO, S. A. P.; RIVITTI, E. A. Glossário dermatológico. In: SAMPAIO, S. A. P.; RIVITTI, E. A. Dermatologia. 3. ed. São Paulo: Artes Médicas, 2007. p. 109-18.

VIEIRA, J. P. Considerações sobre o pênfigo foliáceo no Brasil. São Paulo: Empresa Gráfica da Revista dos Tribunais, 1948.

WHEELER, J. T. Introducción a la semiologia veterinária. In: WHEELER, J. T. Manual de fundamentos de semiologia veterinária (Tomo 1). Rio Cuarto: Fundación Universidad Nacional de Rio Cuarto, 1999. t. 1, p. 11-28. 